\title{
Understanding the interaction between human activities and physical health under extreme heat environment in Phoenix, Arizona
}

\author{
Qunshan Zhao $^{\mathrm{a}, *}$, Ziqi Li ${ }^{\mathrm{b}}$, Dhrumil Shah ${ }^{\mathrm{c}}$, Heather Fischer ${ }^{\mathrm{d}}$, Patricia Solís ${ }^{\mathrm{c}}$, Elizabeth Wentz ${ }^{\mathrm{c}}$ \\ ${ }^{a}$ Urban Big Data Centre, School of Social and Political Sciences, University of Glasgow, Glasgow, G12 8RZ, UK \\ ${ }^{\mathrm{b}}$ School of Geographical and Earth Sciences, University of Glasgow, Glasgow, G12 8QQ UK \\ ${ }^{\mathrm{c}}$ Knowledge Exchange for Resilience, Arizona State University, Tempe, AZ, 85287-5302, USA \\ d Center for Research on Lifelong STEM Learning, Oregon State University, Corvallis, OR, 97331, USA
}

\section{A R T I C L E I N F O}

\section{Keywords:}

ActivityLog

Citizen science

Portable sensing

Urban heat

Community resilience

\begin{abstract}
A B S T R A C T
Long-term community resilience, which privileges a long view look at chronic issues influencing communities, has begun to draw more attention from city planners, researchers and policymakers. In Phoenix, resilience to heat is both a necessity and a way of life. In this paper, we attempt to understand how residents living in Phoenix experience and behave in an extreme heat environment. To achieve this goal, we introduced a smartphone application (ActivityLog) to study spatio-temporal dynamics of human interaction with urban environments. Compared with traditional paper activity log results we have in this study, the smartphone-based activity log has higher data quality in terms of total number of logs, response rates, accuracy, and connection with GPS and temperature sensors. The research results show that low-income residents in Phoenix mostly stay home during the summer but experience a relatively high indoor temperature due to the lack/low efficiency of airconditioning (AC) equipment or lack of funds to run AC frequently. Middle-class residents have a better living experience in Phoenix with better mobility with automobiles and good quality of AC. The research results help us better understand user behaviors for daily log activities and how human activities interact with the urban thermal environment, informing further planning policy development. The ActivityLog smartphone application is also presented as an open-source prototype to design a similar urban climate citizen science program in the future.
\end{abstract}

\section{Introduction}

Community resilience is defined in terms of how communities prepare for, respond to, and recover from shock such as disasters and natural hazards including earthquakes, hurricanes, fire, and flooding (Cutter et al., 2014). Due to the drastic impacts from short-term disasters, existing literature has mostly focused and extensively explored short-term disaster resilience topics via different resilience indicators (social, economic, institutional, policy, infrastructural, environmental, and community capital) (Cutter et al., 2010). Various new forms of data such as social media, fixed sensor network, and remotely sensed imagery have been used to understand the topic with advanced methodologies (i. e. machine learning, Bayesian network, and cyberinfrastructure) (Cai et al., 2018; Li et al., 2015; Mihunov et al., 2020; Zou et al., 2019). However, long-term community resilience, which privileges a long view look at chronic issues affecting communities, has begun to draw more attention from city planners, researchers and policymakers (Cutter, 2020). Long-term, chronic and slow-moving "disasters" can create similar or even higher levels of damage to human communities over the long run. Thus, it is important to understand how communities can learn, respond, and adapt to long-term social, economic, and environmental community stresses (i.e. recurring drought or flooding conditions, long-term heat stress, and sea level rise) (Beheshtian et al., 2018; Ranjan Ram, 2014; Zhao et al., 2020).

Among all of the types of long-term community stresses, extreme cold/heat weather exposure as well as extended periods of winters/ summers, pose a growing health threat to residents in the United States. Although extreme cold weather events and cold-related deaths have received more attention from academic research, media, and government (Howden-Chapman et al., 2012; Vonnak and Zhao, 2020), extreme

\footnotetext{
* Corresponding author.

E-mail addresses: Qunshan.Zhao@glasgow.ac.uk (Q. Zhao), Ziqi.Li@glasgow.ac.uk (Z. Li), dpshah8@asu.edu (D. Shah), Heather.Fischer@oregonstate.edu (H. Fischer), patricia.solis@asu.edu (P. Solís), wentz@asu.edu (E. Wentz).
} 
heat actually ranked as the leading cause of weather-related illness and death (Putnam et al., 2018; Zhao et al., 2018a). The actual number of deaths from heat, however, is believed to be much higher than reported because extreme heat is typically a contributing factor for other causes of death from existing health conditions, such as chronic ischemic heart disease and cardiovascular disease (Shen et al., 1998). This fact poses significant health threats to heat vulnerable individuals (i.e., elderly adults, infants and children) and low-income individuals and families who reply on public transportation, and live in low energy efficiency dwellings and have to pay high utility costs due to the need for AC use (Kovats and Hajat, 2008).

In Arizona, heat-related deaths range up to hundreds of people each year, and may be intimately tied to the activities and actions of heat relief seeking behavior, not just physical exposure. People find relief from the heat in many ways, including public cooling stations (public places where people can find water and indoor shelter from the heat), community pools, urban green infrastructures, and friends' and relatives' homes (Wang et al., 2021b; Wentz and Gober, 2007; Zhao et al., 2018b). This behavior, physical exposure, and vulnerabilities to heat vary greatly across the city landscape (Wang et al., 2021a) and need to be understood from a fine spatial resolution. Furthermore, urban residents sometimes are unaware of the danger presented by the hot physical environment, or lack knowledge where cooling stations are located, may lack resources to protect themselves, or fail to correctly take action to avoid unnecessary heat stroke or other heat-related illness.

Different from natural disasters and hazards, long-term community stress such as exposure to extreme heat is difficult to track and monitor due to the fact that each individual experiences it differently over a long time span, thus it has a peculiar human-centric nature. People, as a kind of sensor, have become sources of multiple data (objective and subjective) ranging from mobility, health risks to perceptions at individual level. Existing research has used small, portable, and affordable data loggers to measure personal heat exposure/individually experienced temperature (Kuras Evan R. et al., 2017). Portable and low-cost sensors such as Maxim Integrated iButton data logger and Onset HOBO data logger are widely used to track personal heat exposure (Bernhard et al., 2015; Kuras et al., 2015). Most of the existing studies target outdoor workers or homeless populations in study areas with extreme heat conditions, such as Phoenix, Arizona, and Tallahassee, Florida (Bernhard et al., 2015; Longo et al., 2017; Uejio et al., 2018). Although continuous and consistent personal heat exposure sensor measurement can provide straightforward understanding of the surrounding heat environment, we cannot fully understand the actual personal heat exposure and health threats without human activity logs and survey responses from individuals (Thompson et al., 2018). A comprehensive set of sensor measurements with human behavior and perception data is necessary to understand and help vulnerable groups, people experiencing homelessness, and outdoor workers reduce their potential health risks from heat during extreme summer temperatures.

Although existing research has explored personal heat exposure by using portable sensors, the sensor data alignment, cleaning, integration, accuracy, quality control, real time monitoring, and analysis remain a significant burden for researchers due to the separated pieces of the data collection process. Furthermore, traditional paper-based questionnaire surveys and activity logs are laborious, erroneous, expensive and temporally less flexible, often with sampling bias due to a lack of robust sampling frames (Thakuriah et al., 2020). Thus, an integrated, affordable, accurate, and readable portable sensing and digital survey/activity log system that can collect and align human activities, locations, time, and urban microclimate data, is effective and necessary.

The goal of this research is to understand how residents living in Phoenix experience, behave, and interact in the extreme heat environment, by providing and assessing a tool and method that improves our ability to link across physical and social datasets. This in turn aims to inform solutions to help mitigate heat stresses, reduce heat-related death/illness, and improve overall health conditions. To achieve this research goal, we designed, created, and evaluated a newly integrated, low-cost, accurate, and readable portable sensing system via smartphone called ActivityLog. We show how this system can collect data efficiently and facilitate urban climate community to do health-related citizen science research, which is typically laborious and expensive. In this research, we evaluate the advantages and disadvantages of paperbased and smartphone-based activity logs from various criterions such as location accuracy, activity log completeness, and environmental sensing effectiveness. The research results can help researchers better understand how human activities interact with the urban thermal environment and inform health and planning policy development. This research is part of the Knowledge Exchange for Resilience (KER) initiative to create a smart data platform and integrate resilience data collected from community stakeholders, social media, citizen science, and local and federal organizations to identify and mitigate resilience threats.

\section{Background}

Researchers continue to design, build, and incorporate smartphone technology into citizen science programs to help manage data collection and submission process. Many researchers develop smartphone applications based on an open-source framework on either iOS or Android platform to facilitate the citizen science data collection via various portable sensors or integrated sensors within the smartphone. Existing examples includes invasive plant detection and biodiversity conservation (Adriaens, 2015; Burr et al., 2014, p. 2; Starr et al., 2014), smart farming (Yu et al., 2017), environmental risk detection (i.e. air quality, chemical contamination, noise) (Blair et al., 2018; Haddad and de Nazelle, 2018; Snik et al., 2014; Zhang et al., 2019), medical data collection and biomedical research (Schmitz et al., 2018; Wogenstein et al., 2018), natural environment monitoring (Bossu et al., 2018; Busch et al., 2016), and inquiry-based science learning (Sharples et al., 2017). Many of the citizen science smartphone applications have been made publicly and freely available on the Apple App Store or Google Play (i.e. enviroCar, LastQuake) (Bossu et al., 2018; Bröring et al., 2015) for general public to download and use. The use of smartphone applications in the citizen science programs make it much faster and easier to collect research data, reduce research cost, as well as improving overall data collection accuracy.

To enable smartphone data collection through citizen science programs, lightweight and low-priced portable sensors (Global Positioning System (GPS), Bluetooth-enabled environmental sensors, etc.) are necessary (Donaire-Gonzalez et al., 2016). These sensors generate continuous streams of fine-grained data with high spatio-temporal resolution, which brings new opportunities for understanding urban environments and urban residents' behavior (Li et al., 2019; Mafrur et al., 2015). In particular, these sensors can capture the location and status of mobile human and non-human objects in cities and their continuous interaction with physical and built environments (Sila-Nowicka and Thakuriah, 2019). The new type of sensor-based in situ information from portable sensing platforms facilitates - even compels - the development of new methodological approaches and analytical frameworks to understand or innovate old and new urban issues.

There are various types of portable sensors that record the behavior and status of the people or objects that carry them (e.g., intensity of activity, physical status, environmental awareness, health status) and characteristics of their surrounding environment (e.g., noise, temperature, air quality) (Al-Dowaihi et al., 2013; Kanjo, 2010; Kanjo et al., 2009; Kao et al., 2009; McKercher et al., 2017; Rabbi et al., 2015; Vlachokostas et al., 2012). While portable sensors are part of the data-intensive science paradigm in the urban big data era, the technology, and the data that they generate require special attention for at least the following reasons. First, it is important to record the mobility/spatial information of moving agents along with other types of sensor information as they navigate the stress or hazard. Therefore, an integration of 
location tracking technologies such as GPS and Radio frequency identification (RFID) are necessary. Second, collected portable sensor information has high spatial and temporal resolution. Consequently, a central advantage of the technology is that it allows the dynamic and near real-time representation and analysis of urban environments and their inhabitants' movements.

Despite the significant potential, there are several limitations of current portable sensing technologies. Compared to stationary sensors, portable sensors tend to have lower data integrity and are mostly carried by human or non-human objects. This will increase the overall sensing errors due to various urban obstacles and frequent indoor/outdoor environment change that induces bias in the data analysis stage (Kanjo et al., 2008). Further, since people spend most of their time indoors compared to outdoors (Höppe, 2002), GPS cannot provide precise location information for the indoor environment. A different location tracking technology is needed to facilitate portable indoor urban sensing. Third, few portable sensors have a good integrated system that provides data display and visualization on smartphones. This prevents smartphone users from understanding their surrounding physical and built environment in real-time, which reduces the value of portable sensing technologies. Additionally, battery consumption, memory/storage, and GPS/Bluetooth connectivity still influence accuracy and completeness of the data collection (Kanjo et al., 2008). Finally, most of the portable sensors and smartphones are still relatively expensive for low-income populations. This is a barrier for researchers and policy makers to study the behaviors and habits of economically disadvantaged populations, who are among those most vulnerable yet who are precisely those who may benefit from more detailed research attention.

\section{Study area and methods}

\subsection{Study area}

The study area focused on the City of Phoenix and City of Chandler within Maricopa County, Arizona (Fig. 1). Maricopa County is home to 27 cities and municipalities including the Cities of Phoenix, Tempe, Mesa, Scottsdale, Mesa, Gilbert, Chandler, Glendale, and Goodyear ("Cities, Towns and Communities in Maricopa County | Maricopa County, AZ," 2019). For the winter months, the annual mean temperature is around $21{ }^{\circ} \mathrm{C}$. This warm and dry climate during the winter season along with a low cost of living, plenty of job opportunities in the public and private sectors, convenient highway and transportation systems, over 300 days of sunshine, and social and cultural amenities make the region as one of the most attractive relocation destinations from cold areas. However, the pleasant wintertime temperatures are in contrast to severe high summertime temperatures. Summer typically lasts from June to September and the summer extreme temperatures in Maricopa County can exceed $49{ }^{\circ} \mathrm{C}$. In summer 2018, the average maximum air temperature is higher than $40{ }^{\circ} \mathrm{C}$ and the average minimum air temperature is higher than $26{ }^{\circ} \mathrm{C}$ (Table 1) (Climate Data Online (CDO), National Climatic Data Center (NCDC), 2021). In Phoenix, the daily highest temperature is reached around $3-5 \mathrm{pm}$, which is difficult for local residents to stay away from the heat since this is an active afternoon time for home-work transit, school pickup, and running errands, etc. The entire area heavily relies on air-conditioning to mitigate heat stress during the summer. The number of indoor heat-related death have continued to increase in Maricopa County over the past 5 years (Harlan et al., 2012; Putnam et al., 2018), which has put many low-income families at risk when they cannot afford the higher summertime cost of running air conditioning.

\subsection{HeatMappers citizen science program}

HeatMappers is a citizen science program in which we recruited volunteers to collect location/time, climate, and human activities data about their heat exposure during their daily life routine. To better understand heat risks in the Phoenix area, HeatMappers volunteers tracked

Table 1

Summer weather conditions from Phoenix airport weather station.

\begin{tabular}{llll}
\hline Month/Year & $\begin{array}{l}\text { Average Maximum } \\
\text { Air Temperature }\left({ }^{\circ} \mathrm{C}\right)\end{array}$ & $\begin{array}{l}\text { Average Minimum } \\
\text { Air Temperature }\left({ }^{\circ} \mathrm{C}\right)\end{array}$ & $\begin{array}{l}\text { Average } \\
\text { Precipitation } \\
(\mathrm{cm})\end{array}$ \\
\hline June 2018 & 40.6 & 26.1 & 0 \\
July 2018 & 42.2 & 30.0 & 1.8 \\
August 2018 & 40.6 & 28.3 & 3.8 \\
September & 40.0 & 26.7 & 1.1 \\
$\quad 2018$ & & & \\
\hline
\end{tabular}

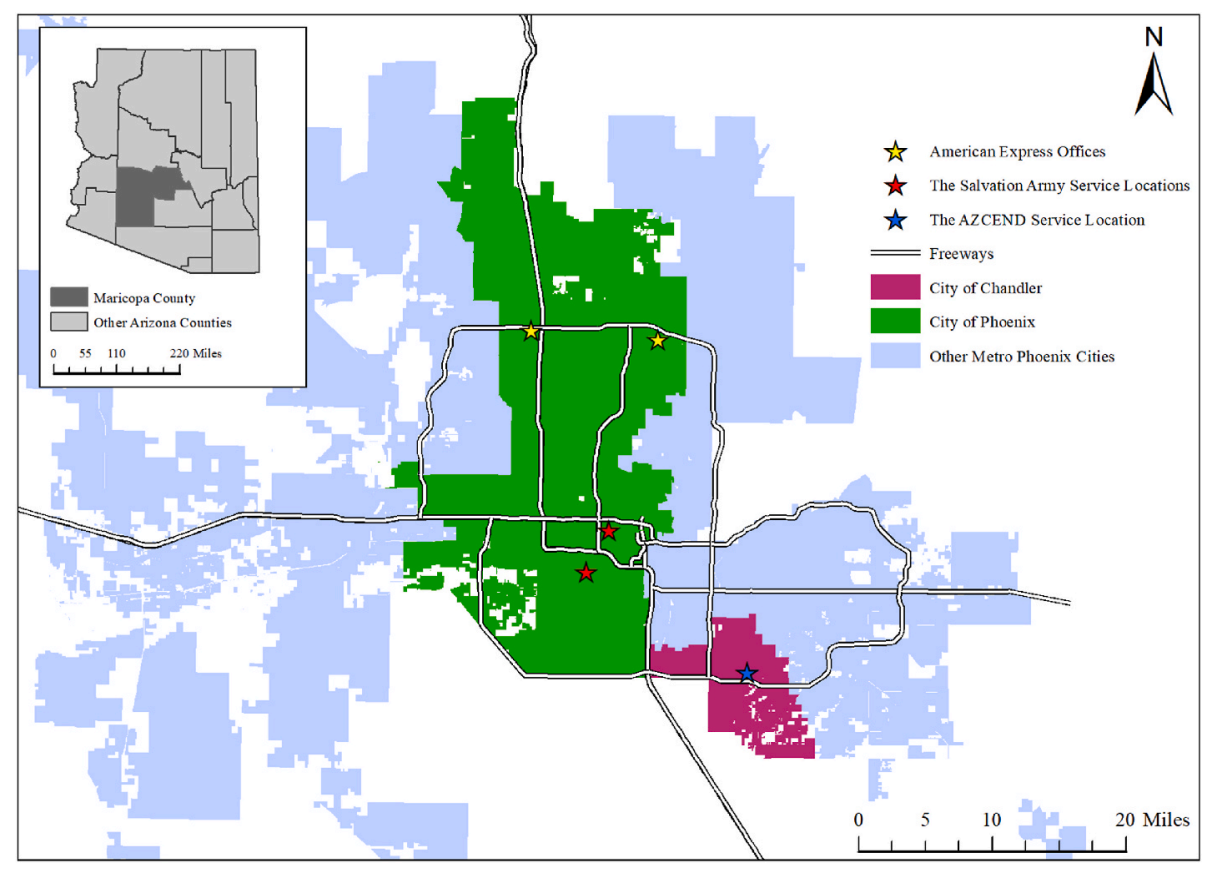

Fig. 1. Study area. 
Table 2

Heat stress index classification.

\begin{tabular}{|c|c|c|}
\hline Classification & Heat Street Index & Effect on the Body \\
\hline Caution & $26.7^{\circ} \mathrm{C}-32.2^{\circ} \mathrm{C}$ & Fatigues possible with prolonged exposure and/or physical activity \\
\hline Extreme Caution & $32.2^{\circ} \mathrm{C}-39.4{ }^{\circ} \mathrm{C}$ & Heat Stroke, heat cramps, or heat exhaustion possible with prolonged exposure and/or physical activity \\
\hline Danger & $39.4^{\circ} \mathrm{C}-51.1^{\circ} \mathrm{C}$ & Heath cramps or heat exhaustion likely, and heat stroke possible with prolonged exposure and/or physical activity \\
\hline Extreme Danger & $51.1^{\circ} \mathrm{C}$ or higher & Heat stroke highly likely \\
\hline
\end{tabular}

\section{My Activity Log Booklet}

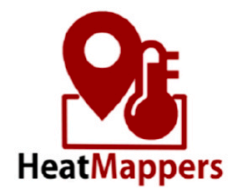

\begin{abstract}
We want to better understand heat risk during certain activities, we would like you to record what activities you are doing throughout your day.
\end{abstract}

\begin{abstract}
Please use this log to record your activities every two hours from 8 am to $8 \mathrm{pm}$ each day of the 10 day study period. If you have a Smartphone you may download and use the MyActivityLog app. instead of this booklet.
\end{abstract}

\begin{abstract}
At the top of the sheet record the date and time, then check off if you are currently inside or outside and what activity you are doing. You may elaborate on the activity on the notes section at the bottom of the sheet.
\end{abstract}

\begin{tabular}{cl} 
My Activity Log & Date: \\
\hline $\begin{array}{c}\text { Where are you Now? } \\
\square \text { Indoors }\end{array}$ & Time: \\
$\square$ Outdoors & \\
Be more specific & $\square$ Shopping \\
$\square$ Home & $\square$ Restaurant \\
$\square$ Work & $\square$ Exercise \\
$\square$ Transit & $\square$ Other
\end{tabular}

Notes:

\section{My Activity Log Date: \\ Where are you Now? Time: $\square$ Indoors Outdoors}

Be more specific

$$
\begin{aligned}
& \square \text { Home } \\
& \square \text { Work } \\
& \square \text { Transit }
\end{aligned}
$$

Notes:

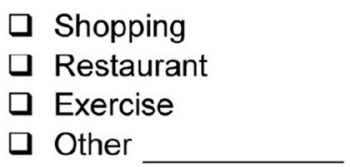

Fig. 2. Paper activity logbook.

their heat exposure both qualitatively and quantitatively. Volunteers were recruited by our community partners (the Salvation Army Metro Phoenix in City of Phoenix ("The Salvation Army Metro Phoenix," 2019) or the AZCEND in City of Chandler ("AZCEND - Feeding Family Needs since 1966," 2019)) and received kits in summer 2018 then began a 10-day study period. These partners serve low-income families, and among other programming, offer utility assistance support to pay electric bills (Zhao et al., 2020). Each kit included an instruction manual and survey (in English and Spanish), an in-home temperature logger (Onset HOBO Temp/RH 2.5\% Data Logger, Part \# UX100-011A), GPS device (Columbus V-900 Bluetooth GPS Data Logger), and a portable climate logger (Kestrel DROP D2 Wireless Temperature \& Humidity Data Logger, SKU 0720). The equipment was housed in a small box, which was mailed back to the university or collected at the drop off points when the study period was over. In the HeatMappers citizen science program, we asked volunteers to carry the portable climate sensor (Kestrel Drops) with the GPS device over a 10-day period to understand their exposure heat environment, and we also gave volunteers in-home temperature sensors to record their in-home temperature at their kitchen or living room.

To measure the real feeling of heat, we used heat stress index measured in the Kestrel Drop in our analysis. The heat stress index is factored by relative humidity and air temperature (National Weather Service, 2019) and the detailed calculation of the heat stress index can be found from the National Weather Service (National Weather Service
Weather Prediction Center, 2014). More details about NOAA's heat street index classification is shown in Table 2 (NOAA, 2021).

The volunteers also filled out a paper activity $\log$ handbook to record their personal activities from 8 a.m. to 8 p.m. during the 10-day period. In the activity log handbook, we asked volunteers to fill in their detailed activities information including general indoor or outdoor locations as well as specific places such as home, work, transit, shopping, restaurant, exercise, and other locations. Volunteers could also fill in activity by themselves in the empty space (Fig. 2). At the end of the HeatMappers citizen science programs, all the participants are asked to fill out a postHeatMappers social survey about their demographic information, life history, household status and infrastructure, health conditions, neighborhood infrastructure, use of utility assistance programs, and use of activity log. The survey was used to collect demographic information from our volunteers as well as information regarding their (and their families) perception of heat risks, their personal actions to find relief from the heat, and habits regarding personal heat mitigation.

\subsection{ActivityLog smartphone platform}

Although activity log data can be collected through the traditional paper-based method with GPS devices in the HeatMappers program, there are many known issues with the existing data collection methods including mismatch of time stamp between sensors, poor hand writing and data missing, high data cleaning and entry cost, limited GPS battery, 


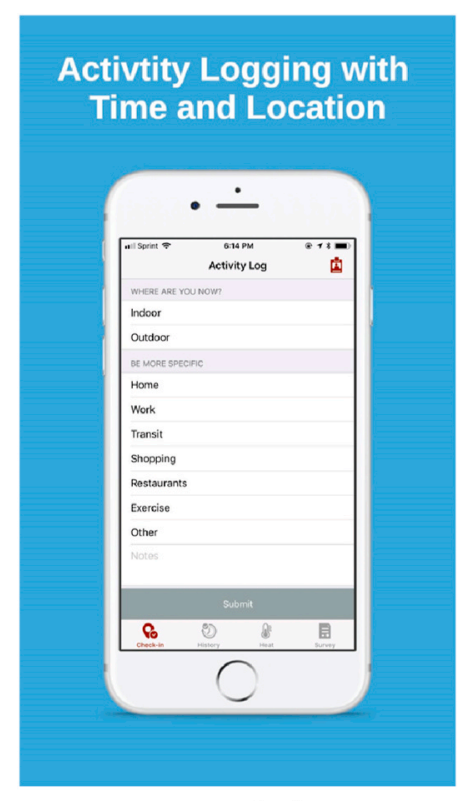

(a)

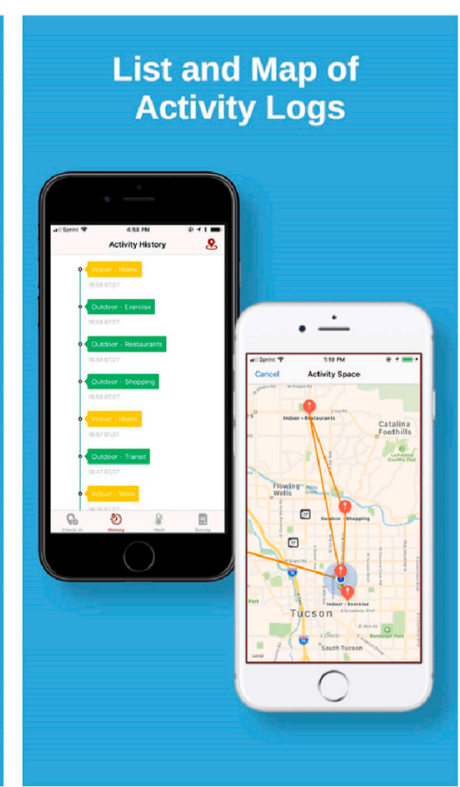

(b)

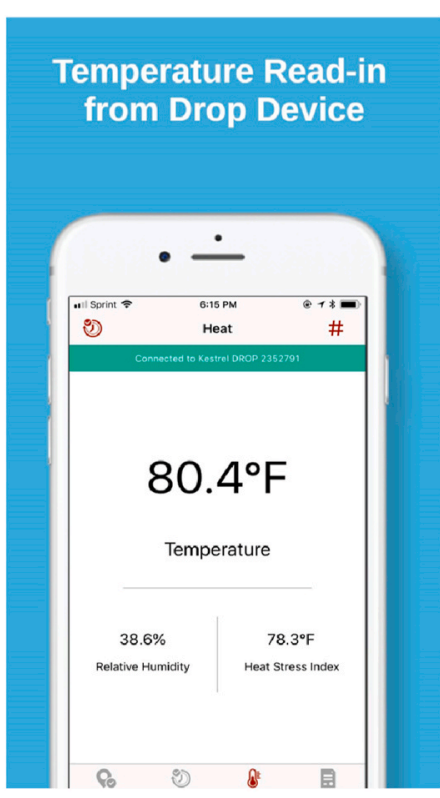

(c)

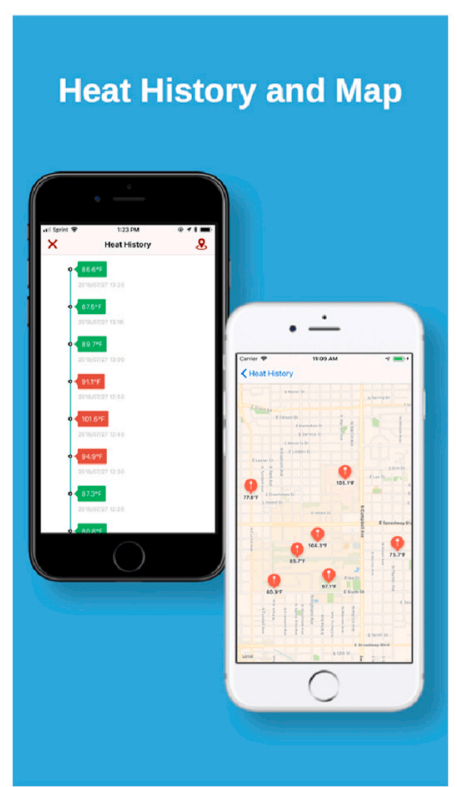

(d)

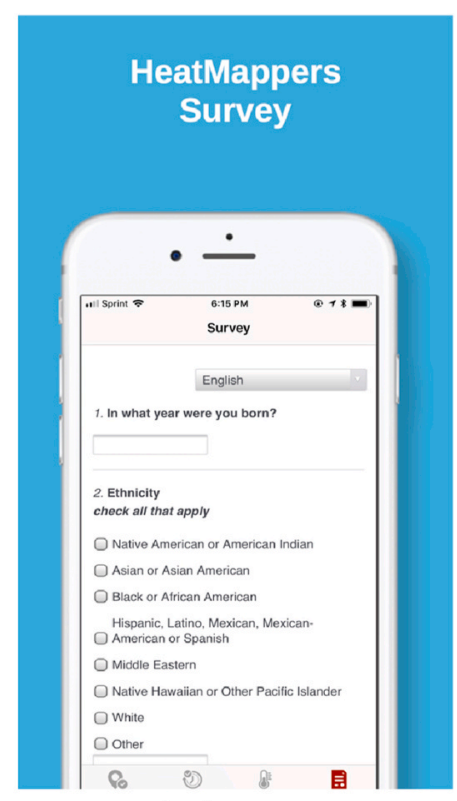

(e)

Fig. 3. ActivityLog mobile application interface (iOS and Android application source codes are publicly available ${ }^{3}$ ).

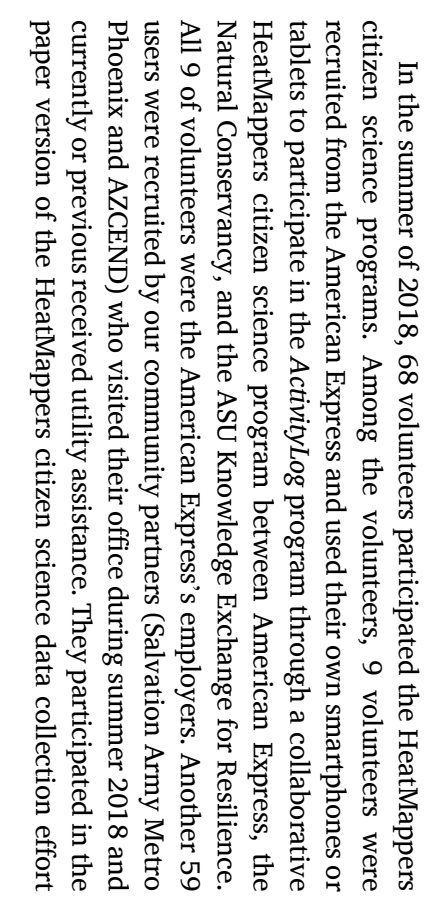

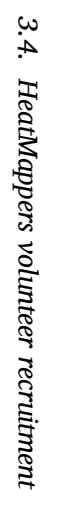

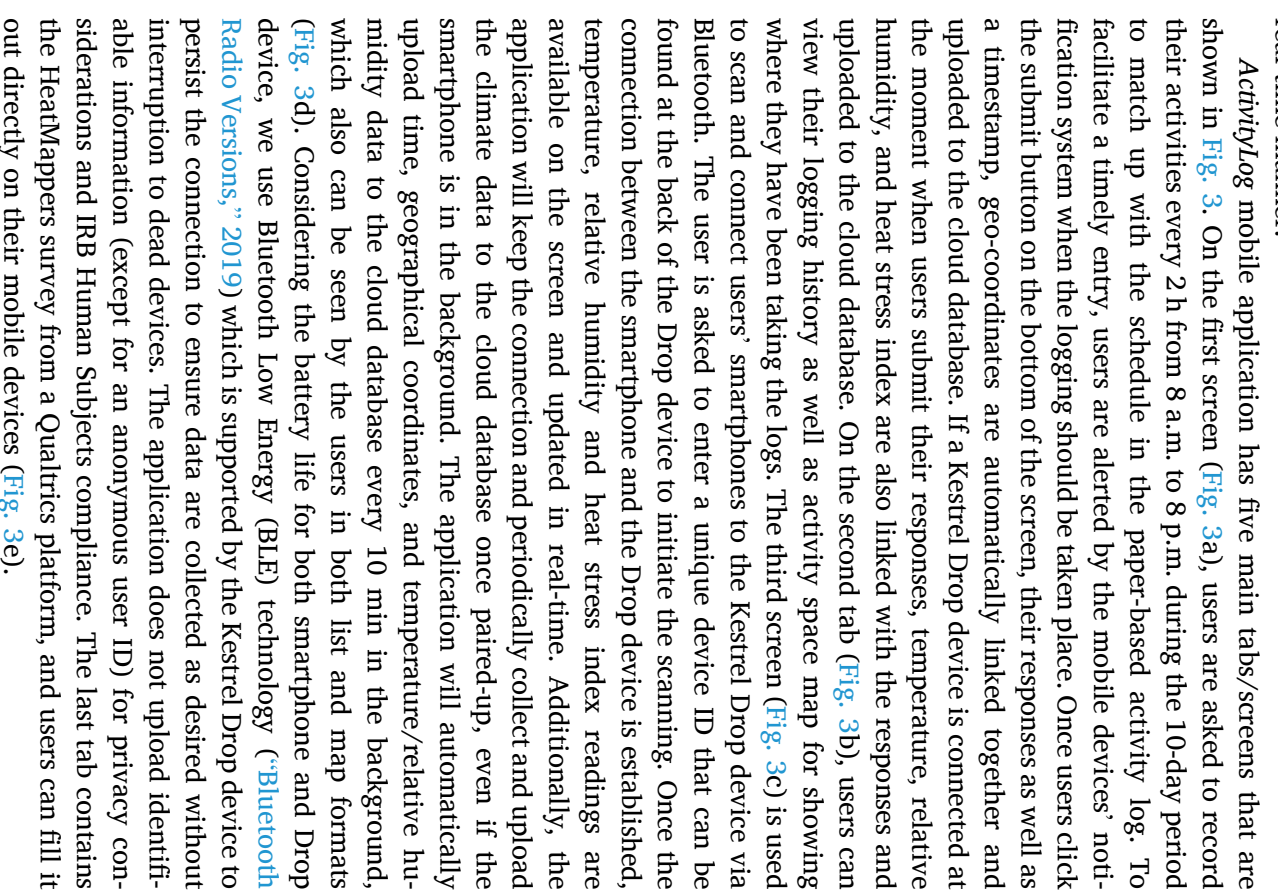

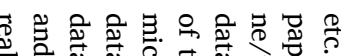

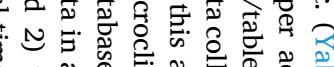

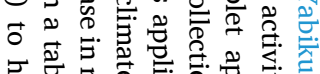
흔 管 을

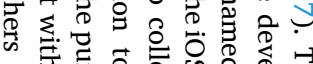

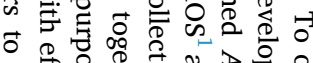

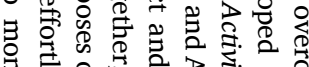

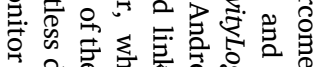

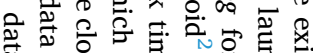
i 等

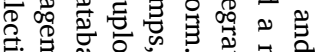
O

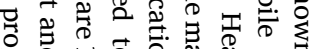

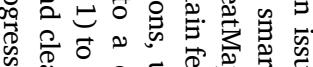

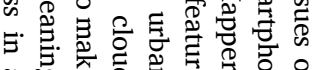


Table 3

Descriptive statistics of survey participants socio-demographic characteristics.

\begin{tabular}{|c|c|c|c|c|c|c|c|c|}
\hline \multirow[b]{2}{*}{ Income (\%) } & \multicolumn{4}{|c|}{ Utility Assistance Group } & \multicolumn{4}{|c|}{ American Express Group } \\
\hline & & & & & & & & \\
\hline Sample Size & \multicolumn{4}{|l|}{37} & \multicolumn{4}{|l|}{7} \\
\hline Less than $\$ 10,000$ & \multicolumn{4}{|l|}{29.7} & \multicolumn{4}{|l|}{0} \\
\hline$\$ 10,000$ to $\$ 29,999$ & \multicolumn{4}{|l|}{18.9} & \multicolumn{4}{|l|}{14.3} \\
\hline$\$ 30,000$ to $\$ 49,999$ & \multicolumn{4}{|l|}{18.9} & \multicolumn{4}{|l|}{14.3} \\
\hline$\$ 50,000$ to $\$ 79,999$ & \multicolumn{4}{|l|}{5.4} & \multicolumn{4}{|l|}{0} \\
\hline$\$ 80,000$ to $\$ 99,999$ & \multicolumn{4}{|l|}{13.5} & \multicolumn{4}{|l|}{42.9} \\
\hline$\$ 100,000$ to $\$ 149,999$ & \multicolumn{4}{|l|}{10.8} & \multicolumn{4}{|l|}{14.3} \\
\hline$\$ 150,000$ or more & \multicolumn{4}{|l|}{2.7} & \multicolumn{4}{|l|}{14.3} \\
\hline \multicolumn{9}{|l|}{ Gender (\%) } \\
\hline Sample Size & \multicolumn{4}{|l|}{44} & 9 & & & \\
\hline Female & 70.5 & & & & 66.7 & & & \\
\hline Male & 29.5 & & & & 33.3 & & & \\
\hline Ethnicity (\%) & & & & & & & & \\
\hline Sample Size & 44 & & & & 9 & & & \\
\hline White & 54.5 & & & & 66.7 & & & \\
\hline Asian or Asian American & 2.3 & & & & 11.1 & & & \\
\hline Hispanic & 13.6 & & & & 11.1 & & & \\
\hline Black or Black American & 13.6 & & & & 0 & & & \\
\hline Native American or American Indian & 2.3 & & & & 0 & & & \\
\hline Mixed & 13.7 & & & & 11.1 & & & \\
\hline Marriage Status (\%) & & & & & & & & \\
\hline Sample Size & 43 & & & & 9 & & & \\
\hline Married or domestic partnership & 39.5 & & & & 44.4 & & & \\
\hline Single & 32.6 & & & & 33.3 & & & \\
\hline Separated & 4.7 & & & & 11.1 & & & \\
\hline Divorce & 18.6 & & & & 11.1 & & & \\
\hline Widowed & 4.7 & & & & 0 & & & \\
\hline Employment status (\%) & & & & & & & & \\
\hline Sample Size & 44 & & & & 9 & & & \\
\hline Employed for wages & 29.5 & & & & 66.7 & & & \\
\hline Retired & 15.9 & & & & 0 & & & \\
\hline A student & 4.5 & & & & 11.1 & & & \\
\hline Out of work and looking for work & 11.4 & & & & 22.2 & & & \\
\hline Homemaker & 9.1 & & & & 0 & & & \\
\hline Unable to work & 13.6 & & & & 0 & & & \\
\hline Other & 16.0 & & & & 0 & & & \\
\hline Education (\%) & & & & & & & & \\
\hline Sample Size & 42 & & & & 9 & & & \\
\hline High School graduate or below & 23.9 & & & & 22.2 & & & \\
\hline Bachelor's degree or some college experience & 64.2 & & & & 55.5 & & & \\
\hline Graduate or professional degrees & 7.2 & & & & 22.2 & & & \\
\hline Prefer not to answer or no specific information & 4.8 & & & & 0 & & & \\
\hline Age & Min & Max & Mean & Std & Min & Max & Mean & Std \\
\hline Sample Size & 44 & & & & 9 & & & \\
\hline & 19 & 76 & 47.7 & 17.2 & 21 & 55 & 37.6 & 10.4 \\
\hline
\end{tabular}

because of the low or irregular smart phone usage and lack of a cellular data plan or WiFi-access.

\section{Analysis and results}

\subsection{Survey participant recruitment and socio-demography analysis}

Fifty-nine volunteers who previously or currently receive utility assistance from the Salvation Army Metro Phoenix and AZCEND participated in our paper-based HeatMappers pilot study from July to September 2018. Information sessions were given by ASU KER research team in the Salvation Army Metro Phoenix office and the AZCEND Chandler office to introduce the HeatMappers citizen science programs to the case workers. Further, case workers recruited volunteers and introduced how to use the HeatMappers citizen science kits. Each of the volunteers carried one Kestrel Drop device and one GPS device, and used a paper-based ActivityLog.

Volunteers from American Express Phoenix offices participated in our ActivityLog pilot study from August to September 2018. Information sessions were given by ASU KER research team in the American Express offices to introduce the HeatMappers citizen science programs and educate volunteers about how to use ActivityLog smartphone applications. All the volunteers downloaded the ActivityLog mobile application and carried one Kestrel Drop device for recording climate data. Because of the various start dates for different volunteers, the study period for American Express volunteers was from August 13 to September 5, 2018.

The detailed descriptive statistics of survey participants sociodemographic information is shown in Table 3. The utility assistance group has more low-income participants compared to American Express volunteers. Gender, ethnicity, and marriage status are similar in both groups. The utility assistant group has more diverse employment status and most of the American Express volunteers are employed for wages. Higher education experience and lower age have also been found in the American Express volunteer group.

\subsection{HeatMappers paper log analysis}

\subsubsection{Descriptive statistics}

Among the 59 volunteers, only 44 volunteers have filled in at least one activity log in the logbook. There are 1,565 activity logs collected on paper from 44 volunteers and the average number of logs for each volunteer is 35.6. We matched the activity logs with Kestrel Drops and GPS devices based on the log time. Only $415 \operatorname{logs}(26.5 \%$ of the logs) 
Table 4

Descriptive statistics of paper and smartphone activity logs.

\begin{tabular}{lll}
\hline & Paper-based Logs & Smartphone-based Logs \\
\hline Total number of volunteers & 44 & 9 \\
Total number of logs & $1565(100 \%)$ & $486(100 \%)$ \\
Indoor logs & $1122(71.7 \%)$ & $365(75.1 \%)$ \\
Outdoor logs & $314(20.1 \%)$ & $121(24.9 \%)$ \\
Other logs with error & $129(8.2 \%)$ & 0 \\
Average number of logs per user & 35.6 & 54.0 \\
Logs matched with location/time data from GPS & $415(26.5 \%)$ & $486(100 \%)$ \\
Logs matched with climate data from Kestrel Drops & $1037(66.3 \%)$ & $258(53.1 \%)$ \\
\hline
\end{tabular}

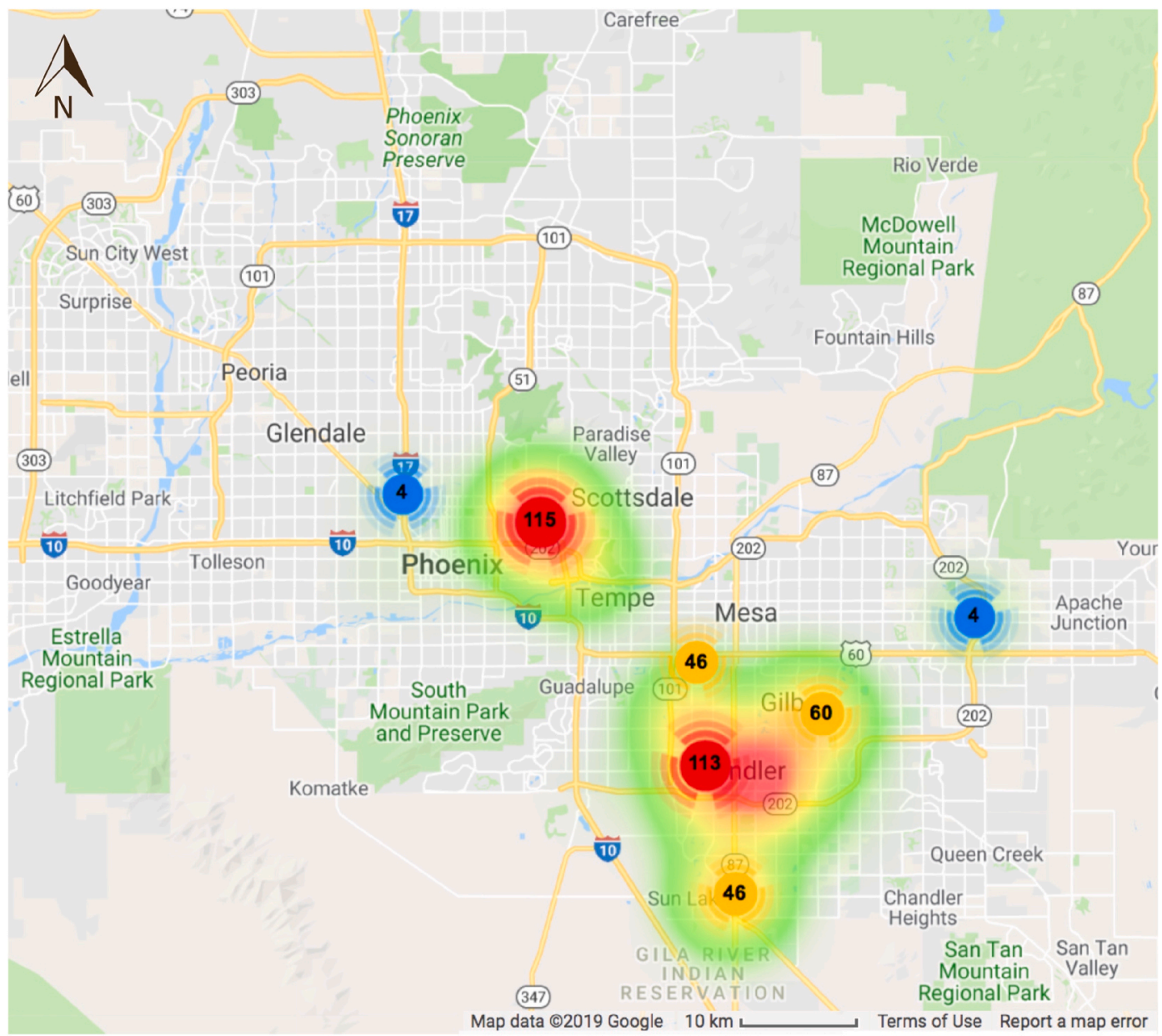

Fig. 4. Spatial distribution of the paper activity $\log { }^{4}$

have location data from GPS device because of the low indoor GPS accuracy and GPS battery limitation as well as the time information missing in the logs. We have successfully matched 1037 paper activity logs $(66.3 \%$ of the logs) with Kestrel Drop climate data including air temperature, relative humidity, and heat stress index (Table 4). The missing data are consequences of the battery limitation of Kestrel Drops and equipment lost. A detailed spatial distribution of the paper activity logs is shown in Fig. 4. We can observe two hot spots near the Salvation Army Metro Phoenix service offices ( $115 \operatorname{logs}$ ) and the AZCEND service office (113 logs). Since most of the volunteers do not own a personal car

\footnotetext{
${ }^{4}$ A geospatial visualization of the paper activity log with time, location, and heat stress index can be found at https://github.com/Resilience-ASU/Activi tyLogPaper/blob/master/Visualization/UtilityAssistance_ActivityLogs_379Log s_Visualization.mp4.
}

and use public transportation, we see a spatially constrained activity space from the maps.

In the paper logbook, volunteers were asked to fill in both their general and specific locations for each log entry. Among all the logs, $1122(71.7 \%)$ of logs were documented as indoor, and $314(20.1 \%)$ of logs were documented as outdoor. $129(8.2 \%)$ of logs identified both indoor and outdoor options at the same time or other locations (Table 4). Further, we asked volunteers to fill in their specific locations. The logbook has 6 fixed options including home, work, transit, shopping, restaurant, and exercise. Besides the 6 fixed options, volunteers can write their specific locations on their own in the blank space. Fig. 5 shows the specific locations distribution from the paper logs. Among the 6 fixed specific locations, $71.0 \%$ of the logs were identified at home with $65 \%$ of the home logs in the indoor environment, following by work (6.0\%), transit (4.4\%), and shopping (2.8\%). Besides the 6 fixed options, we observe some other common locations such as church, library, and 


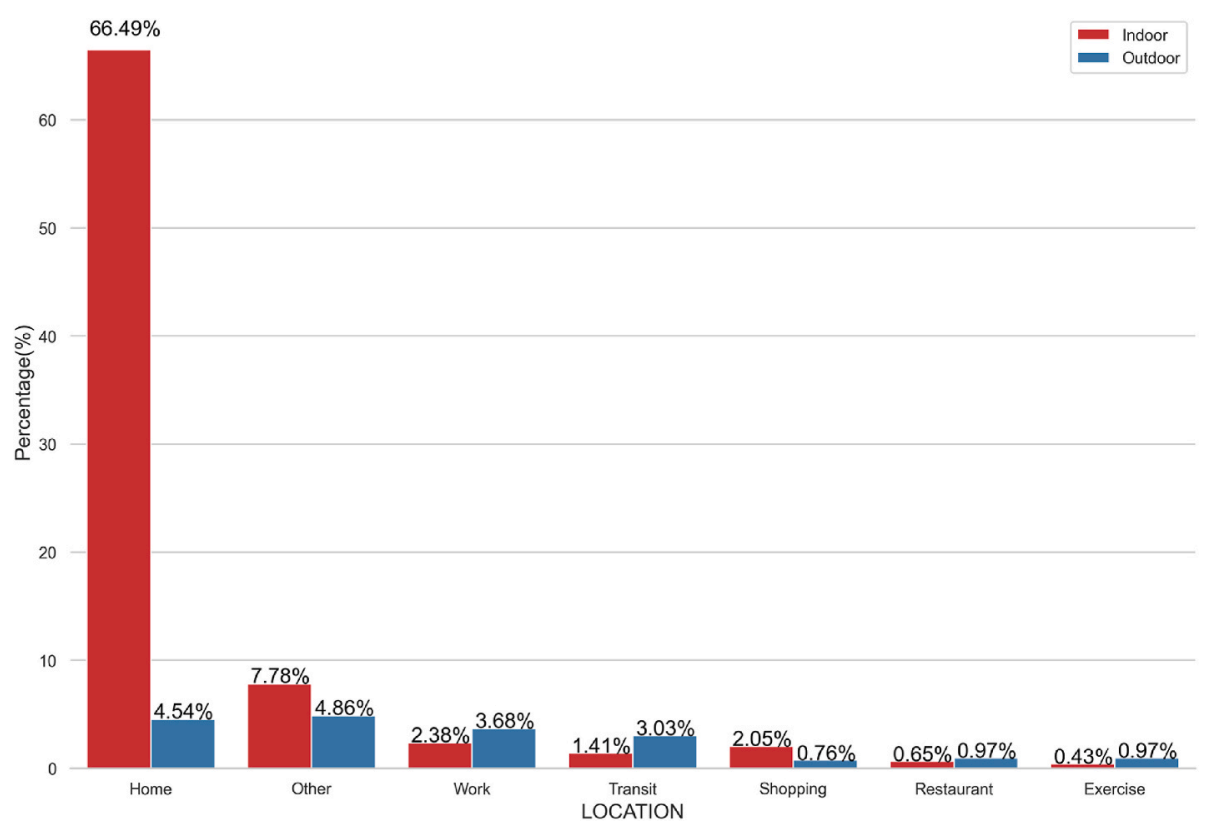

Fig. 5. Activity logs breakdown by category for paper users.

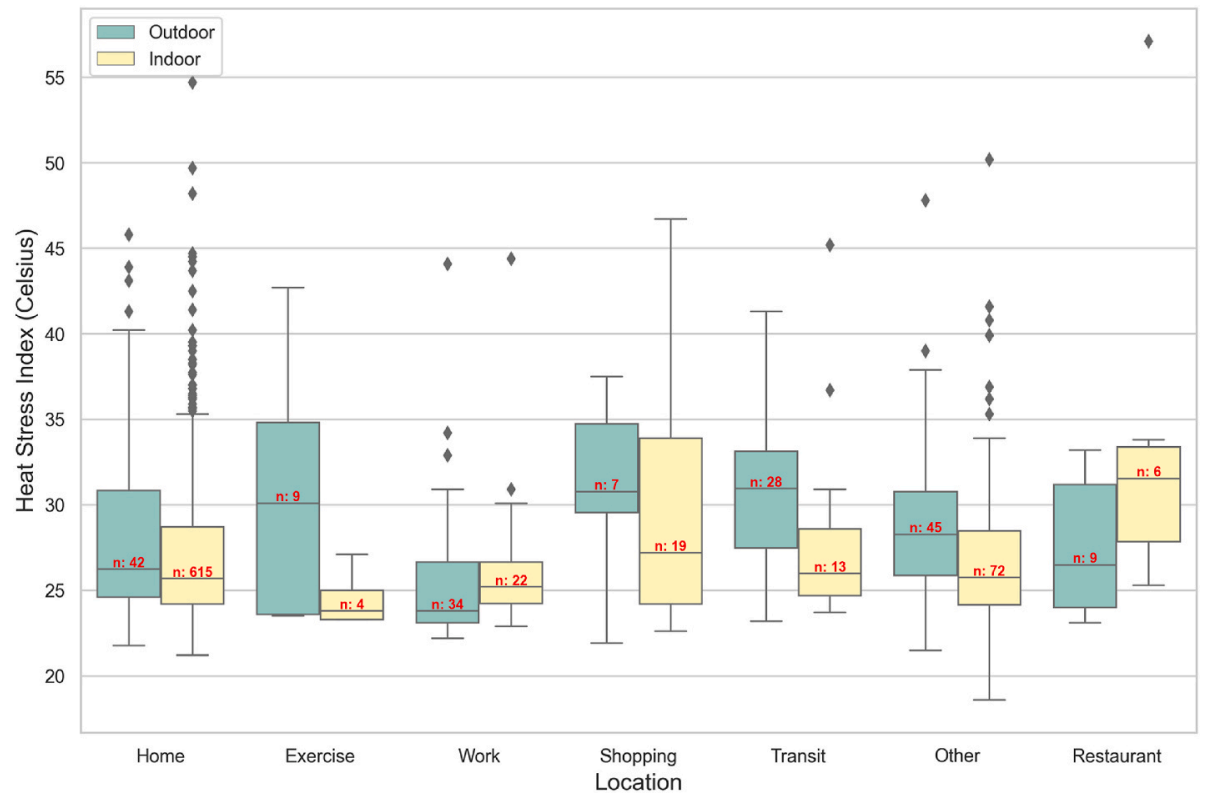

Fig. 6. Heat stress index (unit: ${ }^{\circ} \mathrm{C}$ ) for paper activity log categories (n represent the number of logs in each boxplot).

school, and some volunteers also put multiple options in their response (12.6\% in other category in total).

\subsubsection{Heat stress index analysis}

In this section, we further analyzed the heat stress index for each log category. The accuracy of the climate data heavily depends on whether the volunteers always bring their Kestrel Drops with them during the citizen science programs period. Fig. 6 represents the heat stress index of volunteers from utility assistance groups for both "indoor" and "outdoor" at each specific location category. We observe higher average outdoor heat stress index compared to average indoor heat stress index for most of the categories except work and restaurant categories, and the average indoor/outdoor temperatures are all less than $35{ }^{\circ} \mathrm{C}$. For the home categories, the average outdoor and indoor heat stress indices are very similar. It is worthwhile to mention that among 615 indoor heat stress index observations, we have a large number of observations with the indoor heat stress index higher than $35^{\circ} \mathrm{C}$, including the highest heat stress index of $55^{\circ} \mathrm{C}$. This result certainly warrants further attention for the indoor living environment of the most vulnerable people who receive utility assistance. 


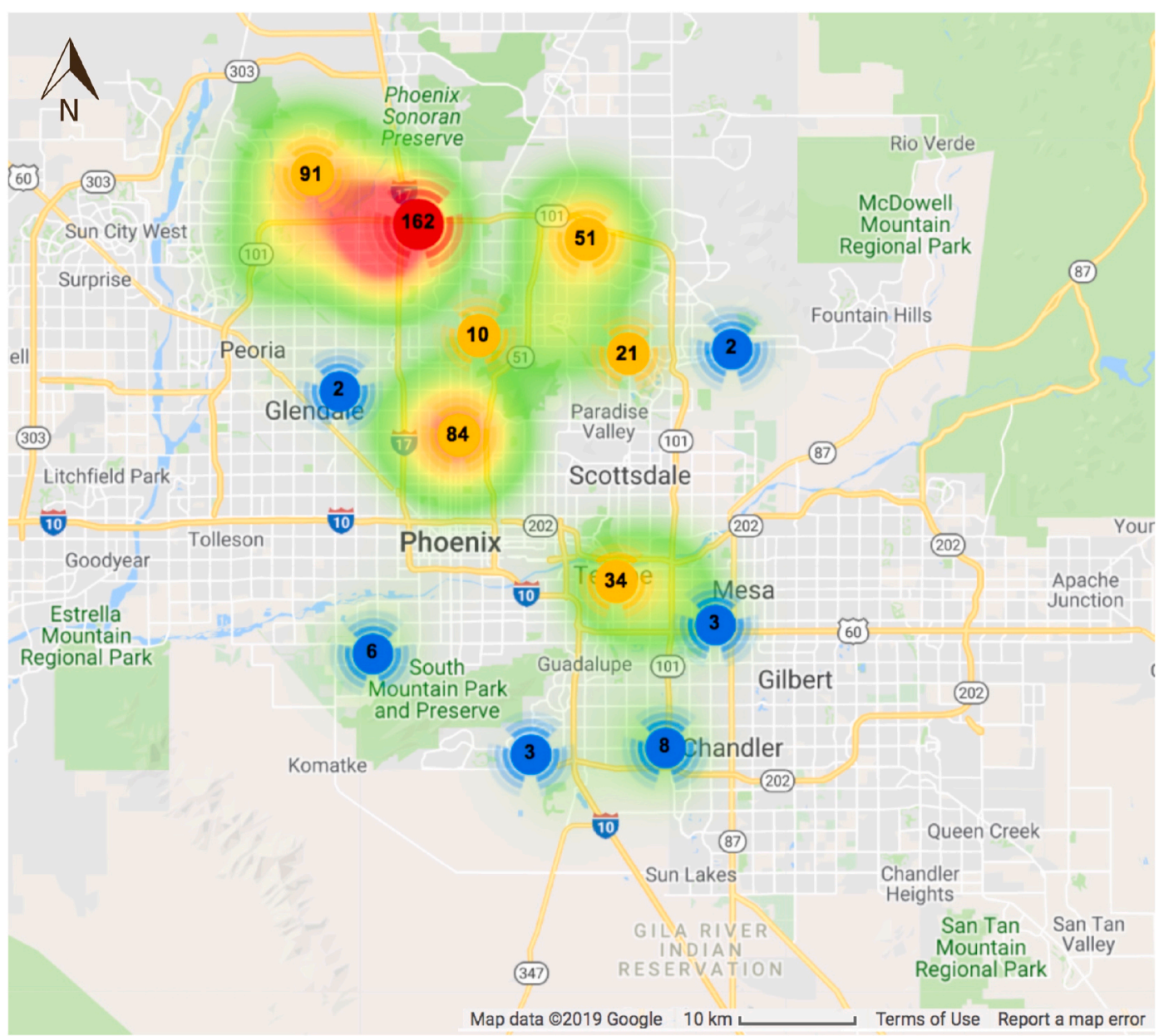

Fig. 7. Spatial distribution of the smartphone activity $\log$. $^{5}$

\subsection{ActivityLog smartphone log analysis}

\subsubsection{Descriptive statistics}

There are 486 activity logs from the smartphone application (54 logs in average per person), and all are associated with time and location. Fig. 7 shows the spatial distribution of the smartphone activity logs from the American Express volunteers. Two American Express office locations have 162 logs and 51 logs on the map. Because volunteers from American Express tend to own a personal car, there are many logs are recorded in the Phoenix metropolitan area such as City of Tempe, Mesa, Chandler, and Phoenix. Among the 486 activity logs, 365 logs (75\%) are indoor logs, and 121 logs (25\%) are outdoor logs. Only 53\% of the logs have climate data from Kestrel Drop because of the Bluetooth distance restriction (15m) (Table 4). We have $100 \%$ of the logs have location data from smartphone location service. The majority of the activity logs (87\%) were located at "home", "work" and "transit" and we do not have any multiple activities category in the smartphone activity log as well (Fig. 8). Besides "transit" and "exercise" activities, most other activities happen in indoor environments.

\subsubsection{Heat stress index analysis}

Fig. 9 represents the heat stress index of American Express volunteers for both indoor and outdoor environments at each specific location. A

\footnotetext{
${ }^{5}$ A geospatial visualization of the smartphone activity log with time, location, and heat stress index can be found at https://github.com/Resilience-AS U/ActivityLogPaper/blob/master/Visualization/AmericanExpress_ActivityLogs _258Logs_Visualization.mp4.
}

consistent higher heat stress index was observed in the outdoor environment for American Express volunteers. The average indoor heat stress indices for "home" and "work" categories are around $26^{\circ} \mathrm{C}$, which represents a consistent use of air conditioning at residential home and working space. "Transit" and "exercise" are categories that need special attention because most of these activities happen in the outdoor environment and the maximum outdoor heat stress index is higher than 40 ${ }^{\circ} \mathrm{C}$. This high level of heat stress may cause heat-related health problems even for the middle-class residents.

\subsection{Location accuracy assessment}

4.4.1. Home location accuracy assessment comparison between paperbased and smartphone-based activity $\log$

To evaluate the effectiveness of collecting volunteers' location information, we compared the location accuracy of the activity log labeled as "home" between paper logs and smartphone logs. The home addresses of users are all collected from the HeatMappers survey. The home addresses were converted into latitudes and longitudes using Google Maps Geocoding API in Python. In the paper log, volunteers used GPS devices to log their location and most of the GPS can only achieve the location precision of $100 \mathrm{~m}$ (i.e., 0.001 arc-degree in latitude and longitude). For analysis consistency, we compare the paper activity log location accuracy and smartphone activity log location accuracy at the precision of $100 \mathrm{~m}$. We successfully identified 255 paper-based logs from 18 volunteers from utility assistance group with a "home" activity log with a location precision of $100 \mathrm{~m}$ or higher. From the smartphone-based activity log, we have a total of $222 \log$ s identified as "home" log from the 9 American Express volunteers. By comparing the home address with the 


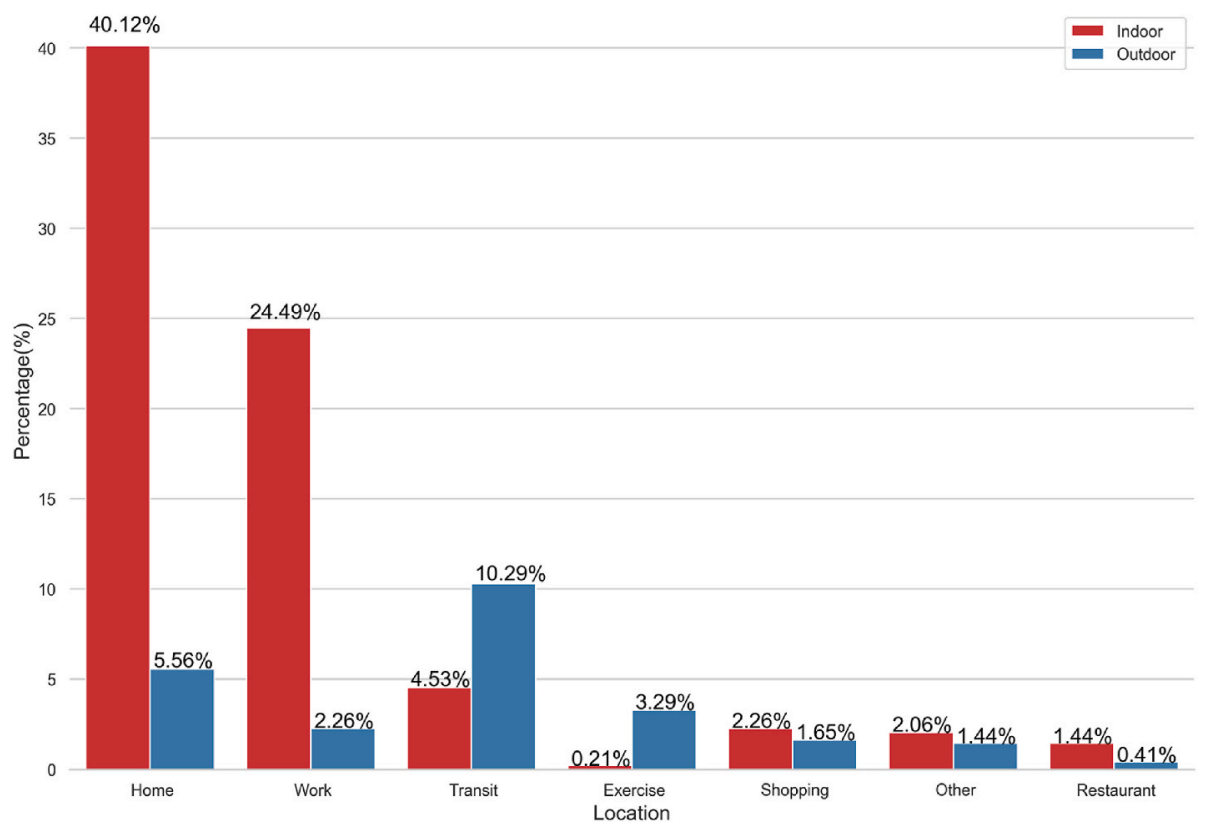

Fig. 8. Activity logs breakdown by category for smartphone users.

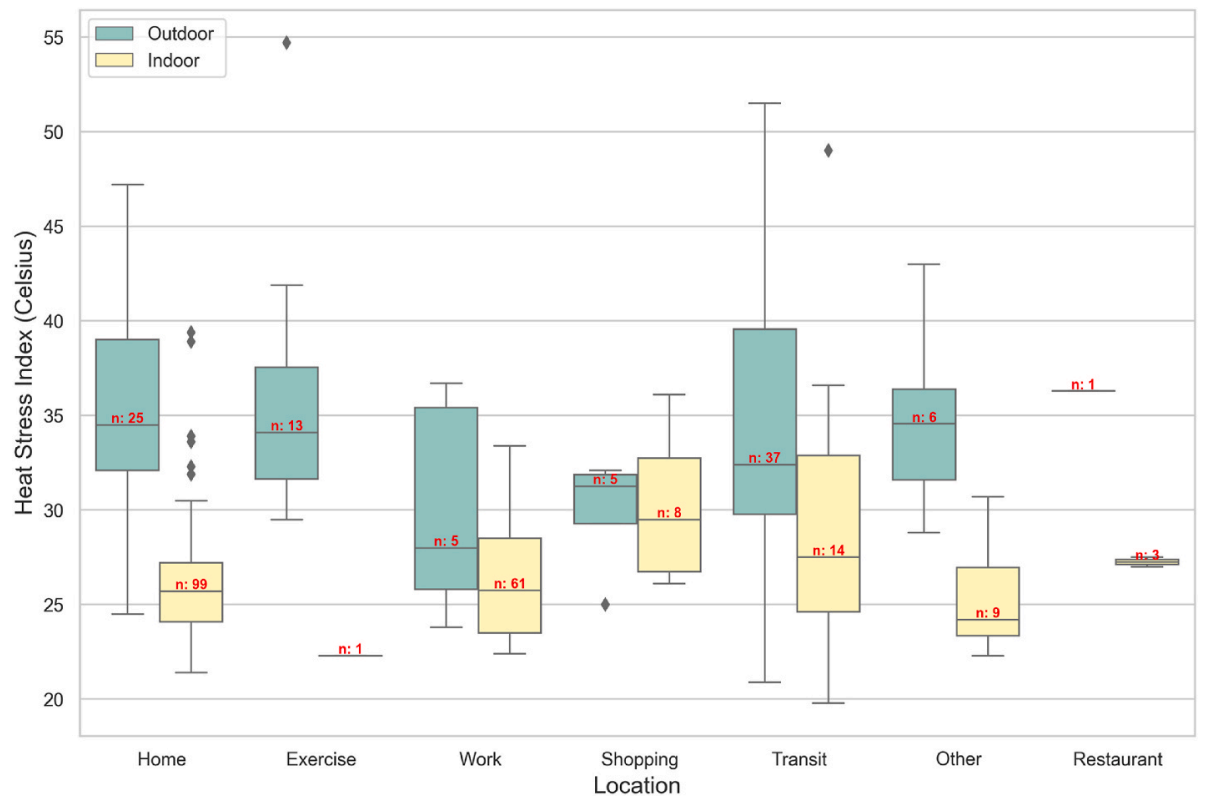

Fig. 9. Heat stress index (unit: ${ }^{\circ} \mathrm{C}$ ) for smartphone activity log categories (n represent the number of logs in each boxplot).

actual locations from specified logs, the overall accuracy at $100 \mathrm{~m}$ precision of the paper-based logs is $65 \%$, and the overall accuracy of the smartphone-based logs is $73 \%$ (Table 5).

By further analyzing our results, there were some interesting patterns in terms of the location accuracy based on user behaviors. Volunteers from the utility assistance group who have a maximum of 10 logs have significantly lower accuracy than the American Express volunteers (50\% vs. $72 \%$ ). However, volunteers from the utility assistance group who have logs between 10 and 50 have much higher logging accuracy $(50 \%$ vs. $79 \%$ ) and have similar accuracy compared to American Express employees (79\% vs. $84 \%$ ). These results shows that the accuracy of paper-based activity logs highly depends on user participation level of the program, and the ActivityLog app generally has higher accuracy with the support of the smartphone location services.
4.4.2. Home and office location accuracy for smartphone activity logs Further, we evaluate and compare the location accuracy of smartphone activity logs at both home and work locations. Since the smartphone uses a combination of built-in GPS, Wi-Fi network and cellular network connection to obtain locations, it has a higher location accuracy compared with GPS devices, especially in the indoor environment. We picked the "home" logs and "work" logs from our smartphone-based activity logs because the majority of our volunteers were in indoor settings (71\%). We obtain volunteers' home address from the HeatMappers survey and their office locations from American Express. Their home and office addresses were geocoded and compared with the location information collected via ActivityLog smartphone application.

In this comparison, we use 0.0001 arc-degree latitude and longitude difference to show a $10 \mathrm{~m}$ location precision. The results show that office logs have $100 \%$ accuracy with 130 logs, but home logs only have $32 \%$ of 
Table 5

Location accuracy assessment and comparison of paper and smartphone activity logs.

\begin{tabular}{lll}
\hline & $\begin{array}{l}\text { Paper-based } \\
\text { Logs }\end{array}$ & $\begin{array}{l}\text { Smartphone-based } \\
\text { Logs }\end{array}$ \\
\hline Number of users & 18 & 9 \\
Total home logs & 255 & 222 \\
$\begin{array}{l}\text { Overall accuracy (100 m precision) } \\
\text { Accuracy for the users less than 10 home }\end{array}$ & $65 \%$ & $73 \%$ \\
$\quad$ logs & $50 \%$ & $72 \%$ \\
$\begin{array}{l}\text { Accuracy for the users who have logs } \\
\text { between 10 and 50 }\end{array}$ & $79 \%$ & $84 \%$ \\
\hline
\end{tabular}

Table 6

Location accuracy assessment and comparison of home and office logs in the smartphone activity logs.

\begin{tabular}{lllll}
\hline & Location Precision & Total Logs & Accurate Logs & Accuracy (\%) \\
\hline Office Logs & $10 \mathrm{~m}$ & 130 & 130 & 100 \\
Home Logs & $10 \mathrm{~m}$ & 222 & 71 & 32 \\
Home Logs & $100 \mathrm{~m}$ & 222 & 162 & 73 \\
\hline
\end{tabular}

accuracy within the $10 \mathrm{~m}$ precision. If we release the location precision to $100 \mathrm{~m}$, the home logs accuracy increases from $32 \%$ to $73 \%$ (Table 6).

\subsection{Survey response rate}

At the end of the data collection period, participants were instructed to complete a survey of 66 questions to gather demographic information, heat related concerns, and awareness of utility assistance programs. We asked 47 multiple choice questions and 19 text input questions. We received completed surveys from 43 out of 59 volunteers from the utility assistance group and all the American Express volunteers participated in the smartphone-based survey. The overall response rate of the survey with smartphone logs is $91.4 \%$, and with paper logs is $73.6 \%$. We obtained a better survey response rate from the smartphone-based survey comparing to paper-based survey, and also higher response rate from multiple choice questions compared to text input questions (Table 7).

\section{Discussion}

By running the HeatMappers citizen science programs in summer 2018, we tested the effectiveness of collecting and understanding heat resilience in Maricopa County, Arizona by using both paper-based activity logs and smartphone-based activity logs. After comparing the smartphone-based activity log results with the traditional paper-based activity $\log$ results, the smartphone-based activity log shows a higher data quality in terms of log completeness, average log numbers per user, activity log and survey response rates, connectivity with GPS and temperature sensors, and overall data accuracy.

There are several drawbacks from the paper activity log version of HeatMappers, which is similar to what was found in Wentz et al. (1999) and Yabiku et al. (2017). First, since our volunteers stay in the indoor environment for more than $75 \%$ of their time, thestandalone GPS device is not able to provide high-quality location information compared to smartphone location services and the battery runs out quickly. This issue causes high rates of missing location data, hampering understanding of the full range of behaviors of utility assistance volunteers. Second, to collect and use the data from hand-written paper activity logs, it requires intensively data entry, cleaning, and merging efforts. Furthermore, we had lost several equipment sets in the process of delivering and returning the volunteer kits. The loss of volunteer kits also decreases the data completeness rate.

We have a "better" Kestrel Drop data match rate with paper activity $\log (66.3 \%)$ to smartphone activity $\log (53.1 \%)$. This is mainly because we match the temperature data with paper activity logs solely based on the log time. It is very difficult to check or validate if our volunteers from utility assistance groups always bring their Kestrel Drops with them, and the actual match rate can be much lower. On the contrary, since the Kestrel Drops need to stay within $15 \mathrm{~m}$ distance to connect with ActivityLog smartphone application, the application ensures the Kestrel Drop captures the urban microclimate information of our volunteers. The temperature data collected from smartphone activity log have a higher data accuracy comparing to paper activity log.

In the results, $71 \%$ of "home" logs were identified by the volunteers from the utility assistance group. At the same time, some of the volunteers experienced higher than $35{ }^{\circ} \mathrm{C}$ indoor heat stress index at home. This is a relatively high indoor heat stress index compared to other public facilities that regularly running air conditioning such as libraries and church (around $27^{\circ} \mathrm{C}$ ). This may be because the volunteers from the utility assistance group intentionally adjust their air conditioning to a relatively higher temperature comparing to other public facilities or cooling stations to save utility cost. We also observe a much higher indoor heat stress index for the utility assistance group compared to the American Express volunteers. This phenomenon requires further attention and interviews with the volunteers from the utility assistance group to further advance our understanding of how low-income populations manage extreme heat during the summer in metro Phoenix.

The ActivityLog app empowers residents with information on personal exposure in the extreme heat summer. This is particularly important for different income groups whose heath exposure can vary dramatically. Low-income residents in Phoenix who stay home in summer still experience a relatively high indoor temperature due to the lack/low efficiency of air-conditioning (AC) equipment or lack of funds to run AC frequently. Middle-class residents fare better in terms of experience with extreme temperatures in Phoenix given more mobility with automobiles and likelier access to frequent AC. Urban residents are sometimes not aware of how hot the physical environment is or not able to avoid unnecessary heat stroke or other heat-related illness (Wang et al., 2021a). With the real time monitoring components of ActivityLog, many of the citizen scientists reported to us that they started to be more aware of their personal heat exposure during the extreme summer. These feedbacks further confirm the importance and necessity of an integrated portable sensing system like ActivityLog to help residents live in Maricopa County to survive the extremely hot summers.

Long term heat resilience is an important and emerging question for urban residents living in extreme heat environments such as Phoenix, Arizona. As urban areas throughout the world are grappling with hotter summers due to climate change, the Phoenix area is becoming a test case for how urban areas could become more resilient to heat (Guardaro et al., 2020; Solís et al., 2020). One contributing strategy is

Table 7

Paper-based and smartphone-based survey response rate comparison.

\begin{tabular}{|c|c|c|c|c|c|}
\hline & $\begin{array}{l}\text { Program participant } \\
\text { numbers }\end{array}$ & $\begin{array}{l}\text { Survey participant numbers (answer } \\
\text { at least one question) }\end{array}$ & $\begin{array}{l}\text { Overall } \\
\text { response rate }\end{array}$ & $\begin{array}{l}\text { Multiple choice questions } \\
\text { response rate }\end{array}$ & $\begin{array}{l}\text { Text input questions } \\
\text { response rate }\end{array}$ \\
\hline $\begin{array}{l}\text { Utility assistance volunteer survey } \\
\text { (paper) }\end{array}$ & 51 & $43(72.9 \%)$ & $73.6 \%$ & $78.9 \%$ & $60.9 \%$ \\
\hline $\begin{array}{l}\text { American Express volunteer } \\
\text { survey (smartphone) }\end{array}$ & 9 & $9(100 \%)$ & $91.4 \%$ & $96.9 \%$ & $77.8 \%$ \\
\hline
\end{tabular}


community-wide data collection efforts to measure and identify vulnerabilities. Another strategy is for individuals to develop self-awareness on how to manage heat. The further refinement and adoption of effective portable sensing systems that unite physical and social data, like ActivityLog, are urgently needed to enable smart mitigation and improve understanding of the detailed lived experiences of human heat exposure in ways that can reduce the health risks for vulnerable groups and low-income populations.

Several limitations exist in this research. First, temperature variation did exist during the entire citizen science programs from July to September. Detailed daily climate/heat-wave information needs to be included to better understand the real-world heat exposure for the program participants. Second, behavioral differences that may have been due to demographic differences across the two samples of participants were not fully explored in this testing phase. We did not ask volunteers from utility assistance groups to use the ActivityLog smartphone application. The main reason is because most participants lacked either a smartphone, or a cellular data plan/WiFi signal to support the data collection. Only a small group of volunteers from American Express helped the program test the ActivityLog smartphone application. The plausible outcome is that there is sampling due to the different socio-demographic factors for these two groups of volunteers (Swindle et al., 2014). Third, the small sample sizes of participants do not allow for stronger statistical tests across groups, but do suffice as proof-of-concept to point to the potential benefits of the tools and methods used in this research. In the future, low-cost Android smartphones or short-term data plans may be purchased for the volunteers from utility assistance programs to facilitate a future round of the HeatMappers citizen science programs. Furthermore, the case workers from the community partners were fully responsible for recruiting volunteers for the citizen science programs. In the future, the research team will adjust the approach to be able to spend more time to help our partners better identify program participants.

\section{Conclusion}

The ActivityLog app is an efficient tool to collect location, time, environment, human activities, and personal survey data in an integrated and low-cost method compared to the traditional separated paper-based survey and portable sensing. Furthermore, the smartphone application serves as an open-source prototype for system citizen science data collection. It facilitates the development of similar citizen science programs in urban communities around health and activity. It is a useful tool grounded in scholarly approaches and methodological experiences, that has the potential to further understand community resilience by facilitating previously burdensome, inaccessible or time-consuming data collection efforts in ways that results could inform planners how urban residents behave in the hot summer; showcasing how human activities interact with the urban thermal environment, and informing further planning policy development.

Data collection tools such as ActivityLog, coupled with solutions such as cooling stations and utility assistance, can be the starting points for creating awareness, both individually and as a community, of the impact of heat and heat exposure. Through awareness, communities can strive toward a range of solutions that protect individuals, especially the most vulnerable. These solutions can then be adapted when events such as very high heat events strain the system further. Tools and approaches that advance integration of community and personal solutions helps us build fundamental knowledge for making our communities more resilient to increasing heat.

\section{Acknowledgements}

The ASU Knowledge Exchange for Resilience is supported by the Virginia G. Piper Charitable Trust. Piper Trust supports organizations that enrich health, well-being, and opportunity for the people of Maricopa County, Arizona. The conclusions, views and opinions expressed in this manuscript are those of the authors and do not necessarily reflect the official policy or position of the Virginia G. Piper Charitable Trust. Dr.
Qunshan Zhao has received UKESRC's on-going support for the Urban Big Data Centre (UBDC) [ES/L011921/1 and ES/S007105/1].

The authors would like to thank the Salvation Army Metro Phoenix, AZCEND, The Nature Conservancy, and American Express for help recruiting citizen science volunteers and organizing the events. We want to thank Mr. Ryan Reynolds, Mr. Sam Golla, and Mr. Maximus Caron for their data cleaning efforts on the paper activity logs, and Dr. Wei Luo's help on activity log data visualization. We also want to thank all of the citizen scientists for providing us with relevant data and contributing to the intellectual development of this work from their lived experiences. Finally, all the insightful comments and suggestions on earlier versions of this manuscript from anonymous reviewers are greatly appreciated.

\section{References}

Adriaens, T., 2015. Trying to engage the crowd in recording invasive alien species in Europe: experiences from two smartphone applications in northwest Europe. MBI 6, 215-225. https://doi.org/10.3391/mbi.2015.6.2.12.

Al-Dowaihi, D., Al-Ajlan, M., Al-Zahrani, N., Al-Quwayfili, N., Al-Jwiser, N., Kanjo, E., 2013. Mbreath: asthma monitoring system on the go. In: 2013 International Conference on Computer Medical Applications (ICCMA). Presented at the 2013 International Conference on Computer Medical Applications (ICCMA 2013). IEEE, Sousse, pp. 1-4. https://doi.org/10.1109/ICCMA.2013.6506169.

AZCEND - Feeding Family Needs since 1966 [WWW Document], 2019. accessed 7.10.19. https://azcend.org/.

Beheshtian, A., Donaghy, K.P., Richard Geddes, R., Oliver Gao, H., 2018. Climateadaptive planning for the long-term resilience of transportation energy infrastructure. Transport. Res. Part E: Logistics and Transportation Review, Making connections: Supply chain innovation research collaboration 113, 99-122. https:// doi.org/10.1016/j.tre.2018.02.009.

Bernhard, M.C., Kent, S.T., Sloan, M.E., Evans, M.B., McClure, L.A., Gohlke, J.M., 2015. Measuring personal heat exposure in an urban and rural environment. Environ. Res. 137, 410-418. https://doi.org/10.1016/j.envres.2014.11.002.

Blair, B.D., Brindley, S., Hughes, J., Dinkeloo, E., McKenzie, L.M., Adgate, J.L., 2018. Measuring environmental noise from airports, oil and gas operations, and traffic with smartphone applications: laboratory and field trials. J. Expo. Sci. Environ. Epidemiol. 28, 548-558. https://doi.org/10.1038/s41370-018-0077-2.

Bluetooth Radio Versions [WWW Document], 2019. Bluetooth technology website. accessed 8.15.19. https://www.bluetooth.com/bluetooth-technology/radio-versio ns/.

Bossu, R., Roussel, F., Fallou, L., Landès, M., Steed, R., Mazet-Roux, G., Dupont, A., Frobert, L., Petersen, L., 2018. LastQuake: from rapid information to global seismic risk reduction. Int. J. Disaster Risk Reduct. 28, 32-42. https://doi.org/10.1016/j. ijdrr.2018.02.024.

Bröring, A., Remke, A., Stasch, C., Autermann, C., Rieke, M., Möllers, J., 2015. enviroCar: a citizen science platform for analyzing and mapping crowd-sourced car sensor data. Trans. GIS 19, 362-376. https://doi.org/10.1111/tgis.12155.

Burr, D., Kline, J., Perryman, A., 2014. A Smartphone Application for Monitoring Gopher Tortoises in Florida, vol. 8. Florida Scientist.

Busch, J., Bardaji, R., Ceccaroni, L., Friedrichs, A., Piera, J., Simon, C., Thijsse, P., Wernand, M., van der Woerd, H., Zielinski, O., 2016. Citizen bio-optical observations from coast- and ocean and their compatibility with ocean colour satellite measurements. Rem. Sens. 8, 879. https://doi.org/10.3390/rs8110879.

Cai, H., Lam, N.S.N., Zou, L., Qiang, Y., 2018. Modeling the dynamics of community resilience to coastal hazards using a bayesian network. Ann. Assoc. Am. Geogr. 1-20. https://doi.org/10.1080/24694452.2017.1421896.

Cities, Towns and communities in Maricopa county | Maricopa county, AZ [WWW document]. accessed 3.10.19. https://www.maricopa.gov/3186/Cities-and-Towns.

Climate Data Online (CDO), National Climatic Data Center (NCDC), 2021. Daily summaries station details: PHOENIX SKY HARBOR INTERNATIONAL AIRPORT, AZ US, GHCND:USW00023183 [WWW document]. accessed 1.2.17. https://www.ncdc. noaa.gov/cdo-web/datasets/GHCND/stations/GHCND:USW00023183/detail.

Cutter, S.L., 2020. The changing nature of hazard and disaster risk in the anthropocene. Ann. Assoc. Am. Geogr. 1-9. https://doi.org/10.1080/24694452.2020.1744423.

Cutter, S.L., Ash, K.D., Emrich, C.T., 2014. The geographies of community disaster resilience. Global Environ. Change 29, 65-77. https://doi.org/10.1016/j. gloenvcha.2014.08.005.

Cutter, S.L., Burton, C.G., Emrich, C.T., 2010. Disaster resilience indicators for benchmarking baseline conditions. J. Homel. Secur. Emerg. Manag. 7 https://doi. org/10.2202/1547-7355.1732.

Donaire-Gonzalez, D., Valentín, A., de Nazelle, A., Ambros, A., Carrasco-Turigas, G., Seto, E., Jerrett, M., Nieuwenhuijsen, M.J., 2016. Benefits of mobile phone technology for personal environmental monitoring. JMIR mHealth uHealth 4, e126. https://doi.org/10.2196/mhealth.5771.

Guardaro, M., Messerschmidt, M., Hondula, D.M., Grimm, N.B., Redman, C.L., 2020. Building community heat action plans story by story: a three neighborhood case study. Cities 107, 102886. https://doi.org/10.1016/j.cities.2020.102886.

Haddad, H., de Nazelle, A., 2018. The role of personal air pollution sensors and smartphone technology in changing travel behaviour. J. Transport Health 11, 230-243. https://doi.org/10.1016/j.jth.2018.08.001.

Harlan, S., Declet-Barreto, J., Stefanov, W.L., Petitti, D., 2012. Neighborhood effects on heat deaths: social and environmental predictors of vulnerability in Maricopa 
county, Arizona. Environ. Health Perspect. 121, 197-204. https://doi.org/10.1289/ ehp. 1104625.

Höppe, P., 2002. Different aspects of assessing indoor and outdoor thermal comfort. Energy Build. Spec. Iss. Therm. Comfort Standards 34, 661-665. https://doi.org/ 10.1016/S0378-7788(02)00017-8.

Howden-Chapman, P., Viggers, H., Chapman, R., O'Sullivan, K., Telfar Barnard, L., Lloyd, B., 2012. Tackling cold housing and fuel poverty in New Zealand: a review of policies, research, and health impacts. In: Energy Policy, Special Section: Fuel Poverty Comes of Age: Commemorating 21 Years of Research and Policy, 49, pp. 134-142. https://doi.org/10.1016/j.enpol.2011.09.044.

Kanjo, E., 2010. NoiseSPY: a real-time mobile phone platform for urban noise monitoring and mapping. Mobile Network. Appl. 15, 562-574. https://doi.org/10.1007/ s11036-009-0217-y.

Kanjo, E., Bacon, J., Roberts, D., Landshoff, P., 2009. MobSens: making smart phones smarter. IEEE Pervasive Comput. 8, 50-57. https://doi.org/10.1109/ MPRV.2009.79.

Kanjo, E., Benford, S., Paxton, M., Chamberlain, A., Fraser, D.S., Woodgate, D., Crellin, D., Woolard, A., 2008. MobGeoSen: facilitating personal geosensor data collection and visualization using mobile phones. Personal Ubiquitous Comput. 12, 599-607. https://doi.org/10.1007/s00779-007-0180-1.

Kao, T.-P., Lin, C.-W., Wang, J.-S., 2009. Development of a portable activity detector for daily activity recognition. In: IEEE International Symposium on Industrial Electronics. Presented at the 2009 IEEE International Symposium on Industrial Electronics (ISIE 2009). IEEE, Seoul, South Korea, pp. 115-120. https://doi.org/ 10.1109/ISIE. 2009.5222001, 2009.

Kovats, R.S., Hajat, S., 2008. Heat stress and public health: a critical review. Annu. Rev. Publ. Health 29, 41-55.

Kuras, E.R., Hondula, D.M., Brown-Saracino, J., 2015. Heterogeneity in individually experienced temperatures (IETs) within an urban neighborhood: insights from a new approach to measuring heat exposure. Int. J. Biometeorol. 59, 1363-1372. https:// doi.org/10.1007/s00484-014-0946-x.

Kuras Evan, R., Richardson Molly, B., Calkins Miriam, M., Ebi Kristie, L., Hess Jeremy, J., Kintziger Kristina, W., Jagger Meredith, A., Middel Ariane, Scott Anna, A., Spector June, T., Uejio Christopher, K., Vanos Jennifer, K., Zaitchik Benjamin, F., Gohlke Julia, M., Hondula David, M., 2017. Opportunities and challenges for personal heat exposure research. Environ. Health Perspect. 125, 085001 https://doi.org/10.1289/ EHP556.

Li, K., Habre, R., Deng, H., Urman, R., Morrison, J., Gilliland, F.D., Ambite, J.L., Stripelis, D., Chiang, Y.-Y., Lin, Y., Bui, A.A., King, C., Hosseini, A., Vliet, E.V., Sarrafzadeh, M., Eckel, S.P., 2019. Applying multivariate segmentation methods to human activity recognition from wearable sensors' data. JMIR mHealth uHealth 7 e11201. https://doi.org/10.2196/11201.

Li, K., Lam, N.S.N., Qiang, Y., Zou, L., Cai, H., 2015. A cyberinfrastructure for community resilience assessment and visualization. Cartogr. Geogr. Inf. Sci. 42, 34-39. https:// doi.org/10.1080/15230406.2015.1060113.

Longo, J., Kuras, E., Smith, H., Hondula, D.M., Johnston, E., 2017. Technology use, exposure to natural hazards, and being digitally invisible: implications for policy analytics. Pol. Internet 9, 76-108. https://doi.org/10.1002/poi3.144.

Mafrur, R., Nugraha, I.G.D., Choi, D., 2015. Modeling and discovering human behavior from smartphone sensing life-log data for identification purpose. Human-centric Comput. Inform. Sci. 5 https://doi.org/10.1186/s13673-015-0049-7.

McKercher, G.R., Salmond, J.A., Vanos, J.K., 2017. Characteristics and applications of small, portable gaseous air pollution monitors. Environ. Pollut. 223, 102-110. https://doi.org/10.1016/j.envpol.2016.12.045.

Mihunov, V.V., Lam, N.S.N., Zou, L., Wang, Z., Wang, K., 2020. Use of Twitter in disaster rescue: lessons learned from Hurricane Harvey. Int. J. Digit. Earth 1-13. https://doi. org/10.1080/17538947.2020.1729879.

National Weather Service, N., 2019. Heat index [WWW document]. URL. accessed 7.4.19. https://www.weather.gov/safety/heat-index.

National Weather Service Weather Prediction Center, N., 2014. Heat index equation [WWW document]. URL. accessed 7.4.19. https://www.wpc.ncep.noaa.gov/html/h eatindex equation.shtml.

NOAA, 2021. What is the heat index? [WWW Document]. accessed 7.26.21. https:// www.weather.gov/ama/heatindex.

Putnam, H., Hondula, D.M., Urban, A., Berisha, V., Iñiguez, P., Roach, M., 2018. It's not the heat, it's the vulnerability: attribution of the 2016 spike in heat-associated deaths in Maricopa County, Arizona. Environ. Res. Lett. 13, 094022 https://doi.org/ 10.1088/1748-9326/aadb44.

Rabbi, M., Pfammatter, A., Zhang, M., Spring, B., Choudhury, T., 2015. Automated personalized feedback for physical activity and dietary behavior change with mobile phones: a randomized controlled trial on adults. JMIR mHealth uHealth 3, e42. https://doi.org/10.2196/mhealth.4160.

Ram, Ranjan, 2014. Technology adoption for long-term drought resilience. J. Water Resour. Plann. Manag. 140, 384-392. https://doi.org/10.1061/(ASCE)WR.19435452.0000329.

Schmitz, H., Howe, C.L., Armstrong, D.G., Subbian, V., 2018. Leveraging mobile health applications for biomedical research and citizen science: a scoping review. J. Am. Med. Inf. Assoc. 25, 1685-1695. https://doi.org/10.1093/jamia/ocy130.

Sharples, M., Aristeidou, M., Villasclaras-Fernández, E., Herodotou, C., Scanlon, E., 2017. The sense-it app: a smartphone sensor toolkit for citizen inquiry learning. Int. J. Mob. Blended Learn. (IJMBL) 9, 16-38. https://doi.org/10.4018/ IJMBL. 2017040102

Shen, T., Howe, H.L., Alo, C., Moolenaar, R.L., 1998. Toward a broader definition of heat-related death: comparison of mortality estimates from medical examiners classification with those from total death differentials during the July 1995 heat wave in Chicago, Illinois. Am. J. Forensic Med. Pathol 19, 113-118.

Sila-Nowicka, K., Thakuriah, P., 2019. Multi-sensor movement analysis for transport safety and health applications. PLoS One 14, e0210090. https://doi.org/10.1371/ journal.pone.0210090.

Snik, F., Rietjens, J.H.H., Apituley, A., Volten, H., Mijling, B., Noia, A.D., Heikamp, S. Heinsbroek, R.C., Hasekamp, O.P., Smit, J.M., Vonk, J., Stam, D.M., Harten, G., van Boer, J. de, Keller, C.U., 2014. Mapping atmospheric aerosols with a citizen science network of smartphone spectropolarimeters. Geophys. Res. Lett. 41, 7351-7358. https://doi.org/10.1002/2014GL061462.

Solís, P., Wentz, E.A., Hondula, D.M., 2020. Resilience and Vibrant Communities, Creating Vibrant Communities: the 113th Arizona Town Hall Background Report. Vitalyst Health Foundation, Phoenix, Arizona.

Starr, J., Schweik, C.M., Bush, N., Fletcher, L., Finn, J., Fish, J., Bargeron, C.T., 2014. Lights, Camera...Citizen science: assessing the effectiveness of smartphone-based video training in invasive plant identification. PLoS One 9, e111433. https://doi. org/10.1371/journal.pone.0111433.

Swindle, T.M., Ward, W.L., Whiteside-Mansell, L., Bokony, P., Pettit, D., 2014. Technology use and interest among low-income parents of young children: differences by age group and ethnicity. J. Nutr. Educ. Behav. 46, 484-490. https:// doi.org/10.1016/j.jneb.2014.06.004.

Thakuriah, P., Vonu), Sila-Nowicka, K., Hong, J., Boididou, C., Osborne, M., Lido, C., McHugh, A., 2020. Integrated Multimedia City Data (iMCD): a composite survey and sensing approach to understanding urban living and mobility. Comput. Environ. Urban Syst. 80, 101427. https://doi.org/10.1016/j.compenvurbsys.2019.101427.

The Salvation Army Metro Phoenix [WWW Document], 2019. The salvation Army metro Phoenix. URL. accessed 7.10.19. https://www.salvationarmyphoenix.org.

Thompson, L., Sugg, M., Runkle, J., 2018. Report-back for Geo-Referenced Environmental Data: A Case Study on Personal Monitoring of Temperature in Outdoor Workers, 1 13. https://doi.org/10.4081/gh.2018.629.

Uejio, C.K., Morano, L.H., Jung, J., Kintziger, K., Jagger, M., Chalmers, J., Holmes, T., 2018. Occupational heat exposure among municipal workers. Int. Arch. Occup. Environ. Health 91, 705-715. https://doi.org/10.1007/s00420-018-1318-3.

Vlachokostas, Ch., Achillas, Ch., Michailidou, A.V., Moussiopoulos, N., 2012. Measuring combined exposure to environmental pressures in urban areas: an air quality and noise pollution assessment approach. Environ. Int. 39, 8-18. https://doi.org/ 10.1016/j.envint.2011.09.007.

Vonnak, R., Zhao, Q., 2020. Fuel poverty and income deprivation in Bristol, UK. In: GISRUK 2020. Presented at the 25th Geographical Information Science Research UK Conference. GISRUK 2020.

Wang, C., Solís, P., Villa, L., Khare, N., Wentz, E.A., Gettel, A., 2021a. Spatial modeling and analysis of heat-related morbidity in Maricopa county, Arizona. J. Urban Health. https://doi.org/10.1007/s11524-021-00520-7.

Wang, C., Turner, V.K., Wentz, E.A., Zhao, Q., Myint, S.W., 2021b. Optimization of residential green space for environmental sustainability and property appreciation in metropolitan Phoenix, Arizona. Sci. Total Environ. 763, 144605. https://doi.org/ 10.1016/j.scitotenv.2020.144605.

Wentz, E.A., Gober, P., 2007. Determinants of small-area water consumption for the city of Phoenix, Arizona. Water Resour. Manag. 21, 1849-1863. https://doi.org/ 10.1007/s11269-006-9133-0.

Wentz, E.A., Vender, J.C., Brewer, C.A., 1999. An evaluation of teaching introductory geomorphology using computer-based tools. J. Geogr. High Educ. 23, 167-179. https://doi.org/10.1080/03098269985443.

Wogenstein, F., Gaul, C., Kropp, P., Scheidt, J., Siebenhaar, Y., Drescher, J., 2018. Design and implementation of a platform for the citizen science project migraine radar. IT Inf. Technol. 60, 11-19. https://doi.org/10.1515/itit-2017-0016.

Yabiku, S., Glick, J., Wentz, E., Ghimire, D., Zhao, Q., 2017. Comparing paper and tablet modes of retrospective activity space data collection. Surv. Res. Methods 11, 329-344. https://doi.org/10.18148/srm/2017.v11i3.6741.

Yu, Q., Shi, Y., Tang, H., Yang, P., Xie, A., Liu, B., Wu, W., 2017. eFarm: a tool for better observing agricultural land systems. Sensors 17, 453. https://doi.org/10.3390/ s17030453.

Zhang, S., Shapiro, N., Gehrke, G., Castner, J., Liu, Z., Guo, B., Prasad, R., Zhang, J., Haines, S.R., Kormos, D., Frey, P., Qin, R., Dannemiller, K.C., 2019. Smartphone app for residential testing of formaldehyde (SmART-Form). Build. Environ. 148, 567-578. https://doi.org/10.1016/j.buildenv.2018.11.029.

Zhao, Q., Dickson, C., Thornton, J., Solís, P., Wentz, E.A., 2020. Articulating strategies to address heat resilience using spatial optimization and temporal analysis of utility assistance data of the Salvation Army Metro Phoenix. Appl. Geogr. 122, 102241. https://doi.org/10.1016/j.apgeog.2020.102241.

Zhao, Q., Fischer, H., Luo, W., Wentz, E.A., 2018a. Community resilience in Maricopa county, Arizona, USA: the analysis of indoor heat-related death and urban thermal environment. In: Frontiers of Geospatial Data Science. Presented at the AutoCarto/ UCGIS 2018, Madison, Wisconsin, p. 1.

Zhao, Q., Sailor, D.J., Wentz, E.A., 2018b. Impact of tree locations and arrangements on outdoor microclimates and human thermal comfort in an urban residential environment. Urban For. Urban Green. 32, 81-91. https://doi.org/10.1016/j. ufug. 2018.03.022.

Zou, L., Lam, N.S.N., Shams, S., Cai, H., Meyer, M.A., Yang, S., Lee, K., Park, S.-J., Reams, M.A., 2019. Social and geographical disparities in twitter use during hurricane harvey. Int. J. Digit. Earth 12, 1300-1318. https://doi.org/10.1080/ 17538947.2018.1545878. 